\title{
First Case of Double T-Cell Receptor Alpha/Delta Rearrangements of $t(11 ; 14)$ and inv(14) and Subsequent JAK2 Rearrangement in a Patient With T-cell Acute Lymphoblastic Leukemia
}

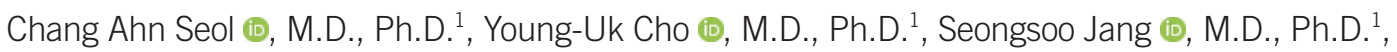 \\ Chan-Jeoung Park (iD, M.D., Ph.D. ${ }^{1}$, Jung-Hee Lee $\mathbb{0}$, M.D., Ph.D. ${ }^{2}$, and Eul-Ju Seo $\mathbb{E}$, M.D., Ph.D. ${ }^{1}$ \\ Departments of ${ }^{1}$ Laboratory Medicine and ${ }^{2}$ Internal Medicine, University of Ulsan College of Medicine and Asan Medical Center, Seoul, Korea
}

\section{Dear Editor,}

Primary cytogenetic abnormalities of T-cell ALL (T-ALL) frequently involve rearrangements between oncogenic transcription factor genes and T-cell receptor (TCR) loci. These are usually mutually exclusive and associated with specific genetic subgroups [1, 2]. We report the first case, to our knowledge, of T-ALL showing distinct and rare abnormalities of sequential TCR alpha/delta (TRA/ $D)$ locus rearrangements associated with $t(11 ; 14)(p 13 ; q 11.2)$, inv(14)(q11.2q32), and clonal evolution of JAK2 rearrangement. This report was approved by Asan Medical Center Institutional Review Board, Seoul, Korea (S2019-1375-0001).

A 21-years-old man was admitted to Asan Medical Center in September 2017, with chest discomfort, petechiae, and oral bleeding. The study period was six months from admission. On admission, his hemogram showed a white blood cell count of $55 \times 10^{9} / \mathrm{L}$ with $68 \%$ lymphoblasts, $141 \mathrm{~g} / \mathrm{L} \mathrm{Hb}$, and $71 \times 10^{9} / \mathrm{L}$ platelets. Computed tomography revealed a mediastinal mass, and a bone marrow (BM) examination showed that $90 \%$ of nucleated cells were lymphoblasts (Fig. 1A). The immunophenotype of the lymphoblasts by four-color flow cytometric analysis (BD FACSCanto II; BD Biosciences, San Jose, CA, USA) was positive for CD2, CD7, CD8, terminal deoxynucleotidyl transferase, and cytoplasmic CD3. The karyotype of the BM cells was 47,XY, del(6)(q13q23), +8,t(11;14)(p13; q11.2), inv(14)(q11.2q32) [13]/46,XY[22] (Fig. 1B). Metaphase fluorescence in situ hybridization (FISH) analysis using the Vysis LSI TRA/D Dual Color Break Apart Rearrangement Probe (Abbott Laboratories, Abbott Park, IL, USA) showed double TRA/D rearrangements associated with $\mathrm{t}(11 ; 14)$ and inv(14) (Fig. 1C), while interphase FISH revealed a single TRA/D rearrangement in $12.5 \%$ of the cells and double TRA/D rearrangements in $74.0 \%$ of the cells (Fig. 1D).

The patient received two cycles of cyclophosphamide, vincristine, doxorubicin, and dexamethasone (hyper-CVAD) for a month and achieved partial remission on day 47. Three weeks later, he was readmitted with disease progression. The follow-up BM examination showed $57.4 \%$ lymphoblasts, increased eosinophils (4\%), and focal fibrosis (MF-1) (Fig. 2A and 2B). The BM karyotype was 47,XY, del(6)(q13q23),+8,t(8;9)(p22;p24),t(11;14)(p13; q11.2),inv(14)(q11.2q32)[20]/46,XY[10] including clonal evolution of $\mathrm{t}(8 ; 9)$ (p22;p24) (Fig. 2C). The $\mathrm{t}(8 ; 9)(\mathrm{p} 22 ; \mathrm{p} 24)$ component showed a JAK2 rearrangement by FISH analysis using the JAK2 Break Apart FISH Probe (Empire Genomics LLC, Buffalo,
Received: February 26, 2019

Revision received: June 3, 2019

Accepted: July 11, 2019

Corresponding author: Eul-Ju Seo, M.D., Ph.D.

Department of Laboratory Medicine, University of Ulsan College of Medicine and Asan Medical Center, 88 Olympic-ro 43-gil, Songpa-gu, Seoul 05505, Korea

Tel: +82-2-3010-4507, Fax: +82-2-478-0884, E-mail: ejseo@amc.seoul.kr

\section{(c) (1) (8)}

(C) Korean Society for Laboratory Medicine

This is an Open Access article distributed under the terms of the Creative Commons Attribution Non-Commercial License (http://creativecommons.org/licenses/by-nc/4.0) which permits unrestricted non-commercial use, distribution, and reproduction in any medium, provided the original work is properly cited. 
A

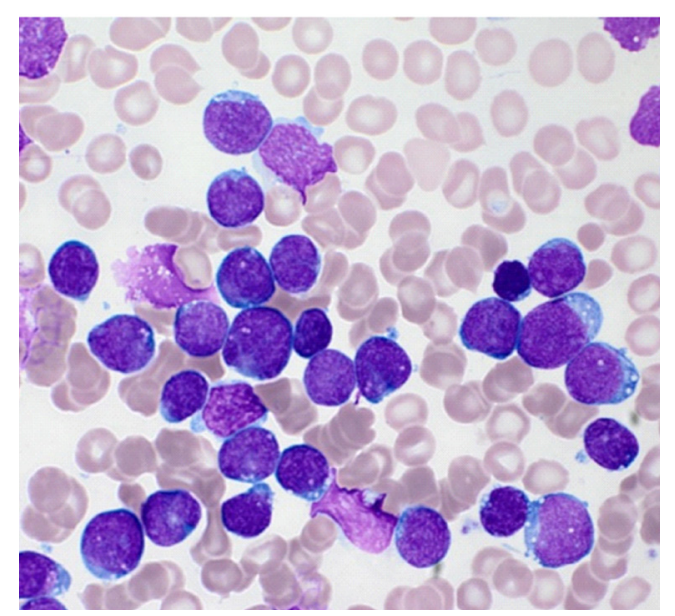

C

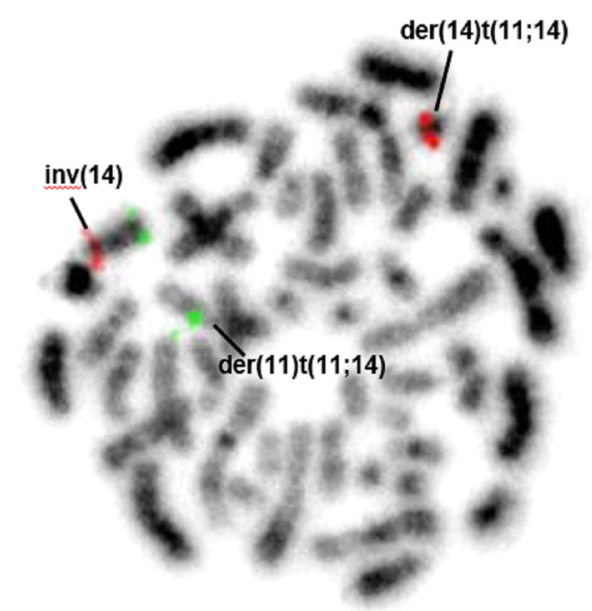

B
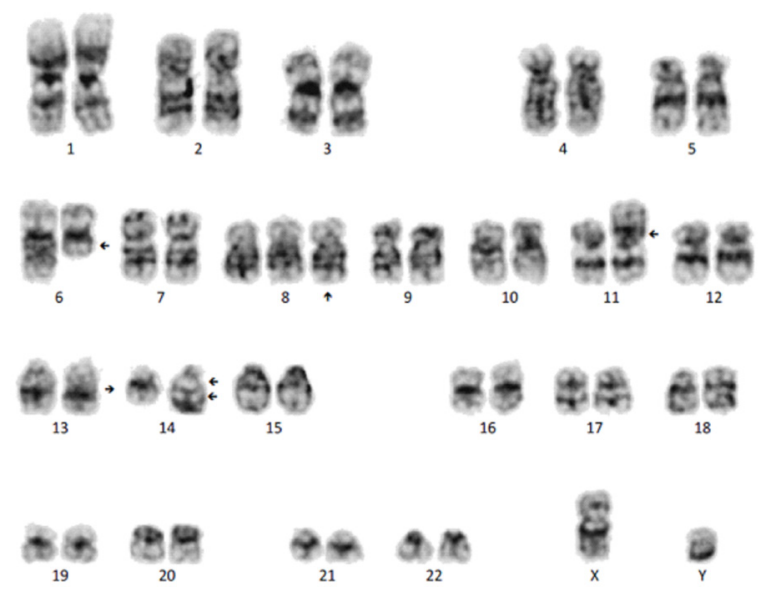

D

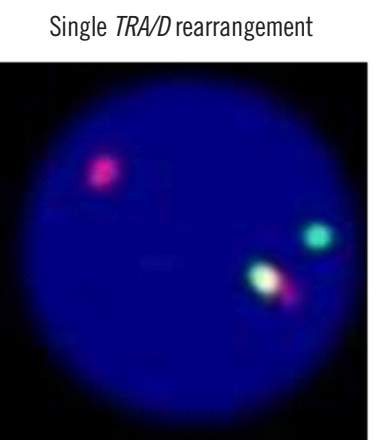

Fig. 1. BM examination, karyotyping, and FISH analysis at diagnosis. (A) Lymphoblasts on the BM aspirate smear (Wright-Giemsa, $\times 1,000$ ). (B) BM karyogram. (C, D) Metaphase and interphase FISH analyses with TRA/D Dual Color Break Apart Rearrangement Probe for 14q11.2 (5'TRA/D: SpectrumRed, 3'TRA/D: SpectrumGreen).

Abbreviations: BM, Bone marrow; FISH, fluorescence in situ hybridization; inv, inversion; der, derivative chromosome; TRA/D, T-cell receptor alpha/delta.

NY, USA) (Fig. 2D). Metaphase and interphase FISH at diagnosis was negative for JAK2 rearrangement. Reverse transcriptase -PCR analysis using several primer sets for hotspot breakpoints of PCM1 (exons 23, 26, 36) and JAK2 (exons 3, 9, 11, 17) failed to detect the PCM1-JAK2 fusion transcript; these are most commonly associated with $t(8 ; 9)(p 22 ; p 24)[3,4]$. Sequencing of NOTCH1 revealed an in-frame deletion of the heterodimerization (HD) domain (NM_017617.5:c.4732_4734delGTG (p.V1578del)) and a nonsense mutation in the proline/glutamic acid/serine/ threonine (PEST) domain (NM_017617.5:c.5707C > T (p.Q2503*)). We further investigated malignant clones, using a bacterial artificial chromosome FISH probe for RP11-162F6 (Aqua, 11p13), which covers the $L M O 2$ gene. FISH analysis using the RP11162F6 and TRA/D probes showed that $\angle M O 2$ was fused with 5'TRA/D in all cells with a single TRA/D rearrangement as well as double TRA/D rearrangements (Fig. 2E). This indicated that $\mathrm{t}(11 ; 14)$ was probably the primary event, rather than inv(14), as a single TRA/D rearrangement was associated with $L M O 2$ rearrangement.

The patient was refractory to chemotherapy regimens. He died four months later, after disease progression.

The $t(11 ; 14)$ (p13; q11.2) component is associated with LMO2 on $11 p 13$ and TRA/D on $14 q 11.2$ and is found in $6 \%$ of T-ALL patients [1]. Nevertheless, inv(14)(q11.2q32) is very rare in TALL. In cases of T-ALL with inv(14)(q11.2q32), possible coexistence with rearrangements of other TCR loci, such as add(7) (q34), $t(11 ; 14)(p 13 ; q 11.2)$ and $t(8 ; 14)(q 24 ; q 11.2)$, has been reported, indicating that inv(14)(q11.2q32) could constitute a combined cytogenetic abnormality causing T-ALL $[5,6]$. BCL11B and TRD may be associated with inv(14)(q11.2q32) [7]. 


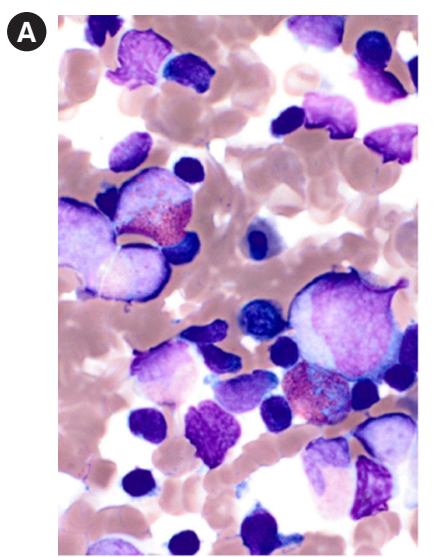

B

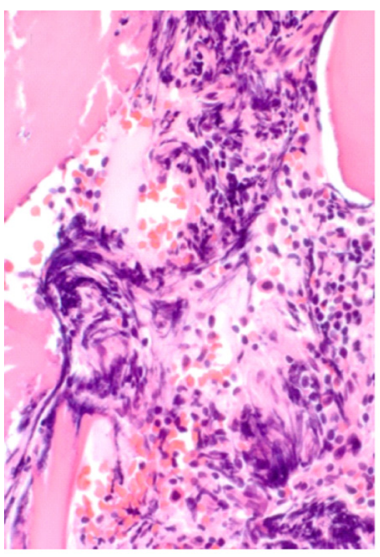

()
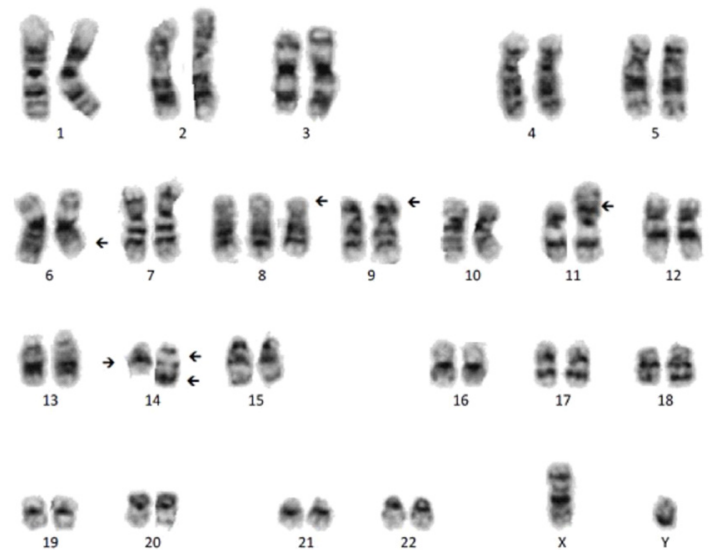

$\boldsymbol{E}$
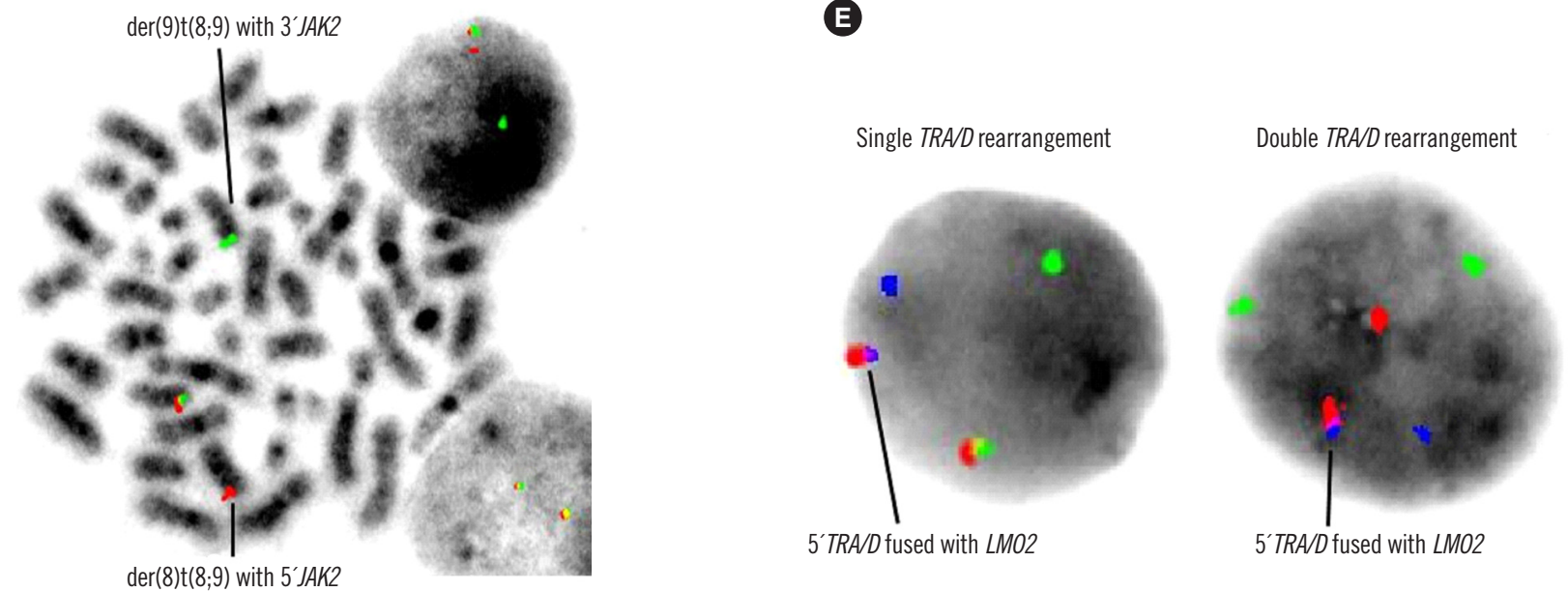

Fig. 2. BM examination, karyotyping, and FISH analysis at follow-up. (A) Eosinophils (Wright-Giemsa, $\times 1,000$ ) and (B) focal fibrosis (HE, $\times 400$ ). (C) BM karyogram. (D) Metaphase and interphase FISH analyses with JAK2 Break Apart FISH Probe for 9p24.1 (5'JAK2: Red, 3'JAK2: Green). (E) Interphase FISH analysis with RP11-162F6 (LMO2) for 11p13 (Aqua) and TRA/D Dual Color Break Apart Rearrangement Probe for 14q11.2 (5`TRA/D: SpectrumRed, 3'TRA/D: SpectrumGreen).

Abbreviations: BM, Bone marrow; HE, hematoxylin and eosin; FISH, fluorescence in situ hybridization; der, derivative chromosome; TRA/D, T-cell receptor alpha/delta.

Most cases in a provisional category of myeloid/lymphoid neoplasms associated with $t(8 ; 9)(\mathrm{p} 22 ; \mathrm{p} 24.1)$ and PCM1-JAK2 are considered myeloid neoplasms, and only a few cases are B-cell ALL (B-ALL) or T-cell lymphoma [8]. A recent study reported that hematopoietic neoplasms with JAK2 rearrangement are extremely rare, and most are associated with PCM1-JAK2 rearrangement [9]. Our patient, who had a JAK2 rearrangement of $\mathrm{t}(8 ; 9)(\mathrm{p} 22 ; \mathrm{p} 24.1)$ as a clonal evolution, shared the characteristics of the entity with PCM1-JAK2 rearrangement such as eosinophilia and fibrosis on follow-up BM examination. A JAK2 inhibitor, such as ruxolitinib, would be effective for treating patients with ALL involving JAK2 rearrangement [10].

The $t(11 ; 14)(p 13 ; q 11.2)$ component was probably the primary cytogenetic event, with inv(14) and $t(8 ; 9)$ occurring successively. Clonal evolutions, dual NOTCH1 mutations, and additional chro- mosomal abnormalities may contribute to a rapidly progressive clinical course. Follow-up cytogenetic evaluations and supporting tests, including FISH, are important to detect cytogenetic clonal evolution.

\section{Author Contributions}

All authors equally contributed to this study. All authors have accepted their responsibility for the entire content of this manuscript and approved submission.

\section{Conflict of Interest}

None declared. 


\section{ORCID}

$\begin{array}{ll}\text { Chang Ahn Seol } & \text { https://orcid.org/0000-0001-8470-7633 } \\ \text { Young-Uk Cho } & \text { https://orcid.org/0000-0002-4403-8989 } \\ \text { Seongsoo Jang } & \text { https://orcid.org/0000-0002-0045-1747 } \\ \text { Chan-Jeoung Park } & \text { https://orcid.org/0000-0003-4396-8348 } \\ \text { Jung-Hee Lee } & \text { https://orcid.org/0000-0002-3127-0068 } \\ \text { Eul-Ju Seo } & \text { https://orcid.org/0000-0002-8247-3746 }\end{array}$

\section{REFERENCES}

1. Belver $L$ and Ferrando $A$. The genetics and mechanisms of $T$ cell acute Iymphoblastic leukaemia. Nat Rev Cancer 2016;16:494-507.

2. Chen B, Jiang L, Zhong ML, Li JF, Li BS, Peng LJ, et al. Identification of fusion genes and characterization of transcriptome features in T-cell acute lymphoblastic leukemia. Proc Natl Acad Sci U S A 2018;115: 373-8.

3. Reiter A, Walz C, Watmore A, Schoch C, Blau I, Schlegelberger B, et al. The $t(8 ; 9)(p 22 ; p 24)$ is a recurrent abnormality in chronic and acute leukemia that fuses PCM1 to JAK2. Cancer Res 2005;65:2662-7.
4. Murati A, Gelsi-Boyer V, Adélaïde J, Perot C, Talmant P, Giraudier S, et al. PCM1-JAK2 fusion in myeloproliferative disorders and acute erythroid leukemia with $\mathrm{t}(8 ; 9)$ translocation. Leukemia 2005;19:1692-6.

5. Liu Y, Easton J, Shao Y, Maciaszek J, Wang Z, Wilkinson MR, et al. The genomic landscape of pediatric and young adult T-lineage acute lymphoblastic leukemia. Nat Genet 2017;49:1211-8.

6. Wilkinson A, Walker DA, Smith NM, Calvert A, Monk AJ, Parkin CA. Inversion (14)(q11q32) in a patient with childhood T-cell acute lymphoblastic leukemia. Cancer Genet Cytogenet 1996;88:76-9.

7. Przybylski GK, Dik WA, Wanzeck J, Grabarczyk P, Majunke S, Martin-Subero JI, et al. Disruption of the BCL11B gene through inv(14)(q11.2q32.31) results in the expression of $\mathrm{BCL11B-TRDC}$ fusion transcripts and is associated with the absence of wild-type BCL11B transcripts in T-ALL. Leukemia 2005;19:201-8.

8. Swerdlow SH, Campo E, et al. eds. WHO classification of tumours of haematopoietic and lymphoid tissues. Revised 4th ed. Lyon: International Agency for Research on Cancer; 2017:78-9.

9. Tang G, Sydney Sir Philip JK, Weinberg O, Tam W, Sadigh S, Lake JI, et al. Hematopoietic neoplasms with 9p24/JAK2 rearrangement: a multicenter study. Mod Pathol 2019;32:490-8.

10. Girardi T, Vicente C, Cools J, De Keersmaecker K. The genetics and molecular biology of T-ALL. Blood 2017;129:1113-23. 